\title{
Burgos: la prensa republicana y anticlerical en la ciudad de los militares y religiosos
}

institucionales.us.es/ambitos/

\section{José María Chomón Serna \\ Universidad de Burgos \\ jmchomon@ubu.es}

English Version: Burgos: the republican and anticlerical press in the city of the military and religious

Burgos, conocida como ciudad de rancho y agua bendita, por la influencia de los militares y religiosos, acogió en el último cuarto del siglo XIX una prensa republicana, obrera y anticlerical muy activa. Fue posible por un grupo de periodistas, cuyos nombres se repiten en la fundación de periódicos defensores de las ideas republicanas. Sufrieron censura, sanciones y prisión. El caso más grave afectó a Nicolás Pasca, condenado a ocho años de cárcel. No se conservan ejemplares de estas cabeceras, que han

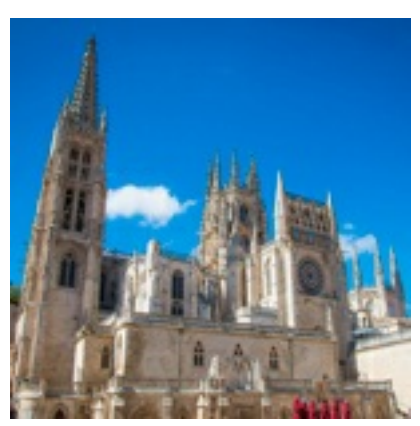
podido ser inventariadas gracias a las escasas referencias halladas en algunos archivos y en los periódicos de la época.

Palabras clave: Burgos, prensa, republicana, anticlerical, oligarquía.

Abstract: In the 19th century in Burgos, which is known as a military and religious city, existed a very active republican and anticlerical press. The existence of this press was possible because of a group of journalists. The names of this group members are often repeated in the foundation newspapers, which defend the republican and anticlerical ideas. These journalists were censored and they also suffered economic sanctions and prison sentences. The most serious case of that was the one of Nicolas Pasca, who received an 8 years prison sentence. Even so, we do not have evidences of this cases and these could have been invented because of the scarcity of sources and information from the documents and newspapers from that century.

Keywords: Burgos, press, republican, anticlerical, oligarchy.

\section{INTRODUCCIÓN}

La prensa se vio sometida en el siglo XIX a un variopinto panorama legislativo, propiciado por la aprobación de hasta siete textos constitucionales, -incluidos el Estatuto Real de 1834 y la Constitución de

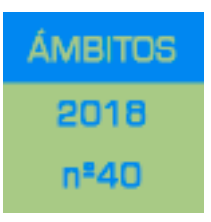
1856, que no llegó a entrar en vigor-, y el desarrollo de una gran variedad de textos legislativos. La inestabilidad política propició la existencia múltiples leyes y normativas en las que se reconoció la libertad de prensa y de otras en las que se sometió a la prensa periódica a un férreo control. 
A esta inestabilidad y presión jurídica, se sumaron las dificultades de los periódicos para sobrevivir. Se trató de una prensa de vida efímera, producto de la debilidad económica de las empresas periodísticas y del amplio porcentaje de analfabetismo entre la población, lo que hacía que los potenciales lectores fuesen una minoría. Los periódicos sobrevivían gracias a los ingresos provenientes de la publicidad y de las suscripciones. Con tirajes reducidos e ingresos publicitarios escasos, su supervivencia fue difícil y, consecuencia de ello, se convirtió en habitual el cierre de cabeceras.

En la España de la Restauración se produjo una proliferación de periódicos. A ello ayudó una legislación más aperturista, los avances en la alfabetización de la población y el uso de la prensa para la promoción social y política. Los periódicos se convirtieron en "fuente de dinero e influencia política" para sus editores y propietarios y sus recursos los obtenían por las ventas, la publicidad y los "fondos reservados o de reptiles". En este sentido Sánchez Illán (1999:54) señala que algunos ministros, especialmente el de Gobernación, "repartían discrecionalmente" dinero del que disponían para "gastos secretos". Este reparto del fondo de reptiles fue perdiendo protagonismo a lo largo de la Restauración y se hizo más habitual "conceder a todos los periódicos, tanto adictos como hostiles, un trato de favor en el encasillado electoral". Lo cierto es que la prensa fue utilizada como trampolín para acceder a cargos políticos.

Desde el punto de vista político lo más destacado en el último tercio del siglo XIX en España fue la hegemonía de dos partidos que se alternaron en el poder de manera sistemática. El Partido Conservador, de Cánovas, que llegó a integrar por su derecha a grupos católicos y tradicionalistas; y el Partido Liberal, de Sagasta.

En este contexto se inició una etapa para la prensa en la que se alternaron períodos de férreo control y otros de mayor aperturismo. La Restauración se inició con fuertes restricciones en materia de prensa. Las cabeceras republicanas fueron suprimidas, se prohibió atacar el sistema monárquico, se aprobaron sanciones que podían llegar al cierre de los periódicos, se crearon tribunales especiales para los delitos de imprenta, se exigió licencia previa y se endurecieron las condiciones económicas para la publicación de periódicos... y, aunque la Constitución de 1876 estableció la libertad de prensa, la legislación concreta limitó este derecho.

Los gobernadores tuvieron amplias potestades para vigilar y sancionar a los periódicos y hacer cumplir las órdenes emanadas desde el Ministerio de Gobernación. El contacto entre los gobernadores en los diferentes territorios provinciales y el Ministerio se hacía mediante telegramas, con la finalidad de que las órdenes se cumplieran de forma inmediata y se impidiera la más mínima posibilidad de que circulase prensa censurada:

Sírvase ordenar el secuestro de los ejemplares del número 22 del periódico La lgualdad, denunciado por los sueltos bajo el epígrafe Crónica vigiliana que inserta en la plana segunda, remitiendo los ejemplares al fiscal de imprenta de esta Corte. [1]

Este es solo un ejemplo de telegramas remitidos desde el Ministerio de la Gobernación al Gobierno Civil de Burgos, ordenando el secuestro y recogida de ejemplares antes de su distribución. Fueron decenas los telegramas idénticos con los que se ordenaba el 
secuestro de cabeceras como La Correspondencia llustrada, El Eco de Madrid, La Mañana, El Siglo, El Constitucional Español, La Nueva Prensa, El Liberal, La Mar, El Mundo Político... [2]

Estos mandatos provocaban la inmediata intervención de los funcionarios, dando cumplimiento a las órdenes de secuestro emanadas del poder central: "Han sido recogidos, en virtud del telegrama de $\mathrm{V}$. E. los números del periódico La Viña, los cuales se remiten hoy al fiscal de imprenta de esa Corte". [3] Los Dos Mundos, El Mundo Político, El Siglo, Los Debates, Gaceta Universal... fueron, entre otros muchos, periódicos secuestrados a su llegada a Burgos, según consta en los legajos del Archivo General de la Administración (AGA). Es evidente que estas mismas órdenes se enviaban a todo el territorio nacional.

La presión gubernamental y legislativa sobre los periódicos políticos no impidió la proliferación de cabeceras de distinto signo político. A mediados de los ochenta existió una prensa republicana, obrera y anticlerical tanto en Madrid como en las capitales de provincia (Marimon, 2013:249). La implantación del liberalismo en España facilitó la creación de esta prensa, que se convirtió en uno de los arietes que golpeó a la Iglesia (Hernández, 2016:62). Según Aubert (196:177), las ideas anticlericales estaban en todos los partidos republicanos y obreristas revolucionarios. La repulsa desde los sectores eclesiásticos a esta prensa y partidos fue enérgica y ello derivó en un diálogo imposible con mutuas descalificaciones (Molina, 1998:289).

La libertad de prensa no comenzó a ser una realidad hasta 1881, cuando el Partido Liberal ocupó por primera vez el poder. En 1883 se aprobó la Ley de Policía e Imprenta, que consolidó la libertad de prensa y sometió los delitos de prensa a la legislación ordinaria. La responsabilidad de lo publicado se concretaba en el director y propietario de la publicación. Esta fue una de las razones por las que en la prensa republicana se recurrió a situar como directores a hombres de paja. Solían ser personas con pretensiones de protagonismo "y lo hacían a cambio de un mísero sueldo" (Seoane, y Saiz, 2007: 135). Aunque la Ley de 1883 fue beneficiosa para la prensa, fue frecuente el recurso al artículo 17 de la Constitución de 1876 que permitía la suspensión de las garantías constitucionales cuando así lo exigía la seguridad del Estado.

En este marco de restricciones y de represión gubernamental y legal (1874-1881) y de mayor libertad (1881-1898) se tuvo que desenvolver la prensa política republicana y anticlerical, que en Burgos fue objeto de sanciones económicas, censura y condenas de cárcel para sus redactores y directores/propietarios.

Los republicanos y socialistas tuvieron una escasa presencia en Burgos y las élites familiares tradicionales dominaron la escena política en la provincia. Ello no impidió la aparición de una prensa local progresista, republicana y anticlerical muy activa, a la vez que minoritaria y efímera. En este contexto cabe destacar, por ejemplo, que en Burgos y Soria se obtuvieran algunos de los mejores resultados de ventas de El Porvenir, el periódico del partido de Ruiz de Zorrilla -fallecido y enterrado en la capital burgalesa-. Y ello tenía una explicación: "Soria era la provincia de origen de Ruiz Zorrilla y en Burgos se concentraban la mayor parte de las propiedades de la familia de su mujer. Eran, por tanto, 
dos provincias donde el líder radical mantenía una fuerte influencia" (Higueras, 2014: 50). Precisamente a esta prensa del Partido Progresista Democrático pertenecieron las sucesivas cabeceras locales que tuvieron su origen en el periódico de El Orden Público.

De esta forma Burgos, conocida como la ciudad de rancho y agua bendita, por la importante presencia e influencia de los militares y religiosos, acogió una activa y desconocida prensa republicana de izquierdas y anticlerical. De sus cabeceras no se conservan ejemplares y existe una escasa documentación o referencias en organismos oficiales y archivos. Las referencias en los archivos (muy escasas), y de Hergueta (1929); y la búsqueda de informaciones insertadas en la prensa de la época que aún se conserva, han hecho posible obtener un inventario de la misma y de los periodistas que se embarcaron en estos proyectos, así como de su adscripción y orientación política.

En su fundación y dirección estuvieron implicados un grupo de periodistas cuyos nombres aparecen de forma sistemática en las diferentes cabeceras que iban apareciendo y desapareciendo.

El nacimiento de esta prensa estuvo vinculado al surgimiento en España de fuerzas sociales y políticas con ideales anticlericales, entre las que se encuadraban todos los partidos republicanos y obreristas. Estos movimientos tuvieron en la prensa periódica un medio para defender y extender sus ideas. Según datos de la Nunciatura en 1898, de un total de 1.078 periódicos existentes en ese momento en España, 204 eran católicos, de ellos 96 políticos; 688 liberales no hostiles a la religión y 186 hostiles a la religión (Revuelta, 2002:177). En los periódicos hostiles solían aparecer contenidos de dura crítica a las instituciones eclesiásticas, que la Iglesia católica consideraba ofensivos (Cárcel, 1988:958).

Tal y como apunta Louzao (2012:77), el anticlericalismo no pudo constituirse como un movimiento social independiente de las organizaciones políticas, especialmente de las republicanas, que lo iniciaron y vehicularon. Quiere decir ello que las cabeceras defensoras de las ideas obreras, republicanas y anticlericales estuvieron vinculadas a movimientos obreros y políticos.

\section{METODOLOGÍA}

El hallazgo y relación de cabeceras republicanas y anticlericales editadas en Burgos es producto de una investigación sistemática de la prensa y periodistas del siglo XIX. Para ello se ha realizado un inventario cuantitativo de todas las cabeceras y su localización en archivos y bibliotecas provinciales y nacionales y en los periódicos que se conservan de la época que insertaron informaciones y contenidos sobre las mismas y sus periodistas.

Asimismo, se ha realizado una completa relación de periodistas y editores que participaron en estas publicaciones periódicas. Junto a la investigación cuantitativa se ha procedido a una recopilación documental de carácter histórico-cronológico de las noticias, entrevistas y comentarios editoriales que tienen relación con el propio desarrollo del periodismo y su posición frente a otros medios de comunicación y a las autoridades y poderes de cada momento. Producto de esta investigación se ha podido realizar un inventario de las cabeceras adscritas al ideario republicano, obrero y anticlerical de la época. 
bibliográficas y hemerográficas -archivos, periódicos del S. XIX, revistas y libros científicos- para obtener datos de la prensa de la época y su proyección social y académica.

Una vez resuelto el estado de la cuestión, se han extraído referencias de periódicos que se conservan, y que han servido para conocer a los precursores de la prensa republicana y anticlerical, así como las sanciones, censura y condenas a las que tuvieron que enfrentarse.

Se ha procedido igualmente a reconstruir la actividad profesional de los periodistas republicanos y anticlericales más destacados y para ello se ha acudido a fuentes archivísticas, bibliográficas y hemerográficas.

\section{CONTEXTO SOCIAL}

La industria de la prensa en el último cuarto del siglo XIX no era ajena a la situación socioeconómica de España, con una población mayoritaria analfabeta, carencia de capitales inversores, amplios sectores dependientes de una agricultura poco productiva, retrasos en la construcción de nuevas infraestructuras de transporte y comunicación y existencia de una industria escasamente desarrollada. Al incremento de la población se sumó un movimiento rural excedente hacia las ciudades. Como apunta Carr (2008:414), la fuerza social más potente aparecida en la Restauración y en las décadas posteriores fue la de los financieros y empresarios industriales, que llegaron a dominar la vida social y económica de las ciudades.

La alfabetización de la población, elemento esencial para afianzar la venta y lectura de periódicos, fue lenta pero progresiva. Los esfuerzos contra el analfabetismo supusieron un incremento potencial de consumidores de prensa. En 1860 un 20 por ciento de la población sabía leer y escribir; un 25 por ciento en 1877 y 29 por ciento en 1887 (Gabriel de, 1997:202).

Los lectores se concentraban en Madrid y en las capitales de provincia. Las grandes capitales, y especialmente Madrid y Barcelona, se configuraron como los centros de mayor producción de prensa. El alto índice de analfabetismo y el elevado precio de la prensa fueron la causa de los bajos tirajes y de que los lectores pertenecieran a las minoritarias clases media y alta: abogados, médicos, maestros, comerciantes, banqueros, industriales...

No existe un censo fiable de las publicaciones periódicas editadas en España en el S.XIX. Se pueden contar por centenares, aunque, como advierte Guereña (1982:82), "se desconocen muchas publicaciones, cuya localización ha sido siempre difícil, a veces infructuosa". Estos datos estadísticos oficiales no son reflejo del número real de cabeceras.

Según los datos de las estadísticas recogidas por Juan Luis Guereña, en 1867 en Burgos había tres periódicos; en 1879 siete; en 1882 seis; en 1887, nueve; y en 1892 nueve. Sin embargo, los anuarios estadísticos no recogieron la totalidad de las publicaciones periódicas reales (Chomón: 2017). En Burgos, y es posible que ocurriera lo mismo en el resto de provincias, el número de cabeceras fue superior al recogido en los datos estadísticos oficiales. 


\begin{tabular}{|c|c|c|}
\hline Año & Periódicos según estadísticas oficiales & Periódicos reales \\
\hline $\mathbf{1 8 6 7}$ & 3 & 3 \\
\hline $\mathbf{1 8 7 9}$ & 7 & 12 \\
\hline $\mathbf{1 8 8 2}$ & 6 & 13 \\
\hline $\mathbf{1 8 8 7}$ & 9 & 14 \\
\hline $\mathbf{1 8 9 2}$ & 9 & 16 \\
\hline
\end{tabular}

\section{Tabla 1: Elaboración propia}

Estos datos reflejan lo que el propio Guereña advertía sobre "la dispersión y la carencia de las fuentes que representan una gran dificultad de la investigación en historia de la prensa". Y es posible que el número de cabeceras fuera superior, ya que de algunas se conoce el año de inicio y se desconoce la fecha de su desaparición. Cazotes y Rubio (2012) mantienen que en menos de un siglo España llegó a tener 1.347 periódicos y ello fue posible por los cambios políticos, sociales y los avances técnicos registrados en el siglo XIX.

Sólo en Burgos entre 1874 y 1899 fueron más de 150 las cabeceras que se editaron, la mayor parte de vida muy efímera. La existencia de un número amplio de publicaciones no fue reflejo de vitalidad de la prensa escrita, sino que representaba todo lo contrario, una cierta inmadurez y la inexistencia de un mínimo sector social interesado capaz de garantizar la supervivencia de las empresas periodísticas por la vía de las suscripciones y venta de sus números (Almuiña, 1996:14). En el último cuarto de siglo, especialmente desde 1880, comenzó a surgir una prensa más profesional, vinculada al desarrollo de la sociedad de masas y a su consolidación como sector económico autónomo (Timoteo, 1981: 385).

Burgos, con apenas 11.000 habitantes a principios de siglo y algo más de 30.000 a finales, era una ciudad administrativa y de servicios en la que desempeñaron un papel fundamental comerciantes, propietarios y profesionales liberales, sobre todo abogados, pero también médicos, catedráticos, y algunos industriales (Castrillejo: 2007:20). De las filas de esta burguesía surgieron la mayoría de los políticos locales y parlamentarios. Eran los propietarios de las fincas urbanas de la ciudad, muchas compradas en la desamortización. La otra cara de la moneda la formaba la inmensa mayoría de la población, afectada directamente por la pobreza o expuestos a ella en los momentos de crisis. Jornaleros, obreros, peones, buhoneros, pobres, criados y mendigos..., conformaban las clases populares, entre las que el proletariado industrial era muy minoritario.

Destacada era también la presencia e influencia de los militares y religiosos. A finales de siglo había del orden de 1.700 militares, es decir, casi el 6 por ciento de la población. La influencia eclesiástica fue también muy importante. Muchos niños eran escolarizados en centros religiosos y a través del Círculo Católico se monopolizó la educación de los adultos. Hubo otros intentos por extender la educación, pero fracasaron debido a la oposición de la Iglesia. En 1882 se constituyó en Burgos la Liga contra la ignorancia 
(Martín, 2003:527), "una institución educativa promovida por la masonería, con el objetivo de formar a los hombres para estar en el mundo, es decir, para servir a la humanidad".

Puede afirmarse, como señala Álvarez (2002:62), que en el terreno de la práctica escolar, "el librepensamiento decimonónico impulsó un contingente de instituciones educativas, entre las que destacaron la Liga contra la ignorancia de Valencia y Burgos en el decenio de 1880". Fue la Logia Iris de Burgos la que promovió esta iniciativa, que tuvo una gestación difícil. Los profesores e integrantes de la Liga contra la ignorancia eran miembros de la Logia y la financiación se obtenía con donativos masónicos o profanos. A pesar de que tuvo cierto éxito en sus inicios, la falta de apoyos, la oposición eclesiástica y la extensión del proyecto del Círculo Católico provocó su cierre.

La Iglesia dispuso además de una red de periódicos afines, que defendieron los ideales católicos y conservadores: El Heraldo de Castilla, La Fidelidad Castellana, La Lealtad Burgalesa, La Verdad o El Castellano... Así, por ejemplo, La Fidelidad Castellana insertó de forma regular en su primera página la serie "El liberalismo es pecado", una colección de artículos escritos por Félix Sardá y Salviny en los que se defendía la tesis pecaminosa que suponía el liberalismo político. Esta colección tuvo una gran difusión entre los periódicos neocatólicos de tendencia ultraconservadora de toda España.

La Iglesia católica de Burgos, con estas cabeceras, atacó a los periódicos liberales y, especialmente, a los que defendieron ideas republicanas y anticlericales. La prensa burgalesa se caracterizó por ser conservadora, reflejo de una sociedad con vértigo a las nuevas ideas y clases sociales, aunque ello no impidió la presencia de iniciativas aperturistas y defensoras de ideas consideradas en aquellos momentos por una buena parte de la población como revolucionarias.

\subsection{La oligarquía política}

Afirman Castrillejo y Fernández (1994:141), que "la élite política burgalesa estuvo dominada entre 1875 y 1923 por oligarquías familiares". En su obra, "Aproximación a un estudio de las élites castellanas durante la Restauración", puede observarse cómo los mismos nombres o los de hermanos o hijos se sucedieron en el Congreso y Senado. Los políticos burgaleses cosieron sobre su electorado redes caciquiles que garantizaban su reelección. De esta forma los escaños tuvieron un carácter casi patrimonial y vitalicio, que se heredaban de generación en generación. Se trató de políticos liberales y conservadores, con escasas diferencias ideológicas, a los que los republicanos y socialistas no hicieron sombra.

Las sagas familiares de Diego Arias de Miranda, Manuel Alonso Martínez, Manuel de la Cuesta y Cuesta o Martínez del Campo dominaron el Partido Liberal en Burgos. Destacó Manuel Alonso y Martínez, que fue uno de los políticos más influyentes de Burgos. Diputado entre la legislatura 20 y 36 (1854-1886), fue también presidente de la Cámara baja desde el 14 de junio de 1889 hasta el 29 de diciembre de 1890. Ministro de Fomento, de Hacienda y de Gracia y Justicia-. La otra gran familia de oligarcas políticos fue la de Martínez del Campo, que ocupó sucesivamente escaños en el Congreso entre 1810 y 1898. Manuel, Antonio, Eduardo y Federico Martínez del Campo fueron congresistas, sucediéndose en el escaño. Manuel Martínez del Campo fue el primero de la saga familiar que resultó elegido en febrero de 1810 con 13 votos de los 21 electores del censo de su 
distrito. Resultó elegido como diputado suplente por el procedimiento para las provincias ocupadas en parte por los franceses. Las Cortes anularon estas elecciones por múltiples defectos.

En el Partido Conservador las familias más destacadas fueron las de Aparicio y Ruiz, Santiago de Liniers y Muguiro. Santiago de Liniers fue diputado por Burgos entre 1884 y 1899. Representó el ejemplo de político cunero. Nacido y fallecido en Madrid (1842-1908), en el año 1900 se le concedió el título de Conde de Liniers. El clan familiar de los Muguiro se inició en la política con José Francisco Muguiro, diputado por Burgos en 1834; al que siguieron Juan Muguiro, en 1836; Fermín de Muguiro, en 1876; Andrés Caballero y Muguiro en 1881 y Juan Muguiro en 1891. Se trató de una familia de banqueros y negocios asentada en Madrid y con una fuerte relación con Burgos. Juan Muguiro, abogado y banquero, construyó en la capital burgalesa el Palacio de la Isla en 1883, en el que se alojó en 1891 la familia Real. Este inmueble, actual sede del Instituto Castellano y Leonés de la Lengua, fue también residencia de Franco entre 1837 y 1839, durante el denominado Gobierno de Burgos.

También se produjeron trasvases políticos. Liberales, como Lorenzo Alonso, hijo de Manuel Alonso Martínez; o Manuel de la Cuesta y Cuesta acabaron en el Partido Conservador. Algunos de estos políticos se apoyaron en la prensa local para extender su influencia e incluso llegaron a dirigir o fundar algunos periódicos, como fue el caso de Víctor Ebro, elegido diputado en 1891 y que fundó el periódico conservador y católico El Heraldo de Castilla, o Aparicio y Ruiz, que dirigió el Caput Castellae, periódico del Partido Conservador. Este político fue elegido consecutivamente diputado entre 1891 y 1923 , es decir, desde la legislatura 37 a la 52. Fue además ministro de Instrucción y Bellas Artes.

\section{PRENSA REPUBLICANA Y ANTICLERICAL EN BURGOS}

Los periódicos políticos del XIX se convirtieron en órganos de confrontación ideológica y en defensores de sus propios ideales. Burgos tuvo un buen número de periódicos de este tipo, en algunos casos muy vinculados a los partidos y, en otros, reflejo de los ideales personales de quienes los patrocinaban y ponían en marcha.

La Oja (1836-1836) puede considerarse como el primer periódico político en Burgos, aunque desconocido, ya que no aparece en ningún inventario ni catalogación de las realizadas hasta la fecha. Fue creado por orden del gobernador, Antonio Ayarza, para la difusión de la propaganda política, con motivo de las elecciones a Cortes. En ese momento era presidente del Consejo de Ministros, Francisco Javier Isturiz Montero. La Oja se elaboró en la redacción del Boletín Oficial de la Provincia (Imprenta de Timoteo Arnaiz), pero su distribución y edición estaban separadas. Se editó con regularidad desde que se anunció su salida en junio, hasta que se celebraron las elecciones, en julio de 1836. En el Boletín Oficial de la Provincia de Burgos número 153 del 17 de junio de 1836 se anunció de esta forma la publicación de La Oja:

La redacción del $B O P$, deseosa de contribuir a la publicación de cuantas noticias puedan interesar al acierto en la elección de los que nos han de representar en las próximas Cortes revisoras, ha tomado a su cargo la impresión de La Oja, acordada por el Sr. 
Gobernador Civil, en la cual se insertarán cuantos discursos, artículos y observaciones se juzguen interesantes a este gran negocio.

En Burgos existió en el siglo XIX una prensa política activa, con periódicos liberales, como El Eco de Castilla (1860-1867) La Voz del Pueblo (1868-1869), El Eco Popular (1869), La Brújula, (1890-1891), El Correo de Burgos, (1896-1898)...; periódicos conservadores, como el Caput Castellae (1877-1880), El Heraldo de Castilla (1880-1881), La Opinión (1885)...; o periódicos carlistas, como El Castellano Viejo (1869-1869), La Fidelidad Castellana (1883-1890), La Lealtad Burgalesa (1889-1991)...

En este contexto de una sociedad conservadora, con enorme influencia de los estamentos militar y religioso y con una clase política dominada por las oligarquías familiares, surgió una prensa republicana y anticlerical, que se caracterizó por sus tiradas muy cortas, vida efímera, vocación e instrumento de propaganda y sus bajos precios. Ejemplo de ello fue El Fomento, que se publicitaba como el periódico más barato de los de su clase.

En la aparición y mantenimiento de esta prensa, un reducido grupo de periodistas aparecen como denominador común de casi todas las cabeceras. Lisardo Blanco, Francisco Vega de la Iglesia, Fernando Lasso de la Vega, Antonio Luna, Nicolás Pasca, Idelfonso Cuellar, Pedro Hernando... fueron algunos de sus principales impulsores. Tuvieron problemas con la justicia y la administración, que les impuso sanciones económicas, secuestros de ediciones y condenas de prisión.

Hubo un semanario, El Papa Moscas (1878-1920), satírico, de orientación liberal (en una de sus etapas se convirtió en periódico del Partido Liberal) y defensor de la libertad de expresión, que destacó por sus numerosas referencias en defensa de los periódicos republicanos y anticlericales, cuando éstos fueron censurados y sancionados. Este semanario y su director, Jacinto Ontañón, también se vieron sometidos por lo menos "a tres secuestros, cinco denuncias, que no prosperaron, más de cuarenta mutilaciones y una causa criminal de tres trimestres y pico" [4].

El Papa Moscas no fue un semanario de izquierdas, revolucionario y anticlerical, pero sí que destacó por la defensa que hizo de las publicaciones republicanas y anticlericales, especialmente del proyecto de El Orden Público y sus sucesivas cabeceras, vinculadas al Partido Democrático Progresista. Sin embargo, también es cierto que mantuvo unas relaciones muy tensas y distantes con Lisardo Blanco y las cabeceras que éste fundó y dirigió. Ello demuestra que probablemente en Jacinto Ontañón, fundador y director de El Papa Moscas, influyeron sus afecciones personales. De hecho, Ontañón apodó a Lisardo Blanco y sus periódicos como "Tropezones".

\subsection{Las cabeceras de El Orden Público}

El Orden Público. Periódico Democrático de la tarde (1880-1883); El Progreso de Castilla (1883-1833); El Orden (1883-1833) y La Voz del Orden Público (1883) fueron todos hijos del mismo proyecto periodístico, que tuvo constantes problemas con la justicia y que llevaron, en más de una ocasión, a sus directores y algunos de sus redactores a prisión. Los procesos judiciales, secuestros, censuras y sanciones económicas a las que se vieron sometidos fue la causa del cambio constante de cabeceras para sortear la prohibición de su publicación. 
El Orden Público fue fundado por Idelfonso Cuellar el 11 de enero de 1880. Esta cabecera, que se publicaba en días alternos, salió a la escena periodística cumpliendo con los requisitos y autorizaciones legales. Con fecha 7 de enero de 1880 el Ministerio de la Gobernación concedió la correspondiente autorización para su publicación. Fue por tanto un periódico que nació con los permisos gubernamentales preceptivos:

Cumpliendo con lo dispuesto por V. E. en su respetable comunicación de fecha 1 del 12 último, he autorizado a D. Idelfonso Cuellar, vecino de esta ciudad, para publicar en la misma un periódico político con el título El Orden Público. Lo que tengo el honor de poner en conocimiento de $\mathrm{V}$. E. a los efectos que proceda ${ }^{[5]}$.

Se trató de una cabecera muy activa políticamente, que participó de forma directa en la promoción y oposición de movilizaciones sociales:

La manifestación intentada el jueves, y que se anunció por carteles con colores nacionales, no pudo tener lugar, según unos, por causa del mal tiempo, y según otros, para evitar alguna colisión, pues no todos estaban conformes con ella, a juzgar por el suplemento que nuestro colega El Orden Público repartió y fijó en las esquinas. Unos y otros fueron después rotos por algunos particulares y por agentes de la policía, que, sin duda, tendrían órdenes concernientes para ello" [6].

El Orden Público estuvo publicándose, con múltiples dificultades, durante tres años consecutivos. En 1883 se produjo una operación de fusión y creación de nuevas cabeceras, todas adscritas también al Partido Democrático. Fue una manera de sortear los impedimentos administrativos y legales para su publicación. De esta forma se fundó El Progreso de Castilla (1883-1883), cuyo primer ejemplar se publicó el 5 de abril de 1883. Esta cabecera estuvo dirigida por Francisco Vega de la Iglesia, y en la misma también escribieron otros periodistas de ideas republicanas y de izquierdas, como Nicolás Pasca y Antonio Luna. Fue de vida muy efímera. El 21 de septiembre de 1883 desapareció y se refundó con El Orden Público, que a su vez anunció que dejaba de publicarse, siendo sustituido por El Orden, dirigido por Pedro Hernando, conocido abogado-periodista de convicciones republicanas, que participó en proyectos periodísticos, bien como director o colaborador:

Nuestro apreciable colega El Orden Público, anunció el viernes a sus lectores la desaparición del estadio de la prensa, sustituyéndole, con parte de su redacción, otro colega con las mismas tendencias, titulado El Orden a secas. Ayer se dijo también la posibilidad que habría de refundir El Progreso de Castilla en el primero de dichos cofrades ${ }^{[7]}$.

El nuevo periódico duró muy poco, 17 días después, el 7 de octubre, se publicó un suplemento en el que se informó que cesaba su publicación por hallarse los redactores en la cárcel. La cabecera de El Orden surgió, al contrario de lo que hizo su predecesor, sin la autorización y permisos a los que la ley obligaba. Por ello fueron encarcelados el director y algunos de los redactores. como Nicolás Pasca, Francisco Vega de la Iglesia o el repartidor de El Orden Público, acusados de "publicación clandestina" [8].

Muy poco después, en noviembre, se editó La Voz del Orden Público, que se editaba los miércoles, viernes y domingos: 
Dícese que hoy aparecerá un nuevo periódico titulado La Voz del Orden Público, sucesor de El Progreso de Castilla y redactado por los mismos señores que confeccionaban este mismo órgano del Partido Democrático. Deseamos a sus redactores mejor suerte que la que hasta aquí han tenido, y menos visitas al Buque de Santa Águeda [9].

Tras la aparición del primer ejemplar de La Voz del Orden Público los problemas con la censura se volvieron a suscitar. De hecho, su primer número fue prohibido y secuestrado.

\subsubsection{Censura y condenas de prisión}

Estas cabeceras fueron órgano republicano zorrillista y revolucionario, según uno de sus impulsores, Francisco de Vega de la Iglesia. En las mismas trabajaron republicanos de Burgos como el propio Vega de la Iglesia, Restituto Collantes, Antonio Luna, Nicolás Pasca, Vicente García y García, Eduardo Chao, Rafael Cervera, Manuel Pedregal, José Muro, José Rivera, Antolín Gutiérrez Mariscal, Teodoro Rueda, Ángel Álvarez Taladrid, Julián Arbolo, Fermín Herrán, Eduardo Méndez Ibáñez, Federico Fernández Izquierdo, Demetrio Duque, Ángel Cecilia, Julio García de Quevedo, que firmaba con el seudónimo de J. Sincent y Mo, Félix Cecilia...

Sufrieron censura, secuestros, cierres, multas y algunos de sus periodistas fueron encarcelados y denunciados por publicación clandestina e injurias y calumnias. Además, fueron censurados por la autoridad eclesiástica y el Ayuntamiento.

El Orden Público, fue secuestrado al poco de publicarse, en enero de 1880. Su tercer número no pudo ver la luz. Los agentes de la autoridad se personaron en la redacción para impedir la venta del periódico y recoger los ejemplares. El gobernador de Burgos remitió al Ministerio de la Gobernación un telegrama en el que notificaba el secuestro del periódico:

Ha sido denunciado el periódico que se publica en esta Capital con el título El Orden Público, número 3, correspondiente al día de ayer y secuestrados todos los ejemplares, de acuerdo con el Fiscal de Imprenta de esta Audiencia [10].

En este telegrama no se mencionan las razones concretas de la denuncia y secuestro. El periódico salió bien parado de este proceso y resultó absuelto por la Audiencia de Burgos:

El Orden Público ha sido absuelto; luego ya tenemos Orden para algún tiempo, caso de que no le vuelvan a desordenar. Es decir, Orden Público, periódico Democrático de la tarde, porque orden público de todo el día y de toda la noche, tenemos más de lo que merecemos. Que cuando Dios da no es escaso [11].

El Progreso de Castilla también fue denunciado por el gobernador, Manuel Somoza de la Peña -acusado de injurias al rey- en junio de 1833, que remitió por telegrama al Ministerio de la Gobernación la explicación de su actuación:

Adjunto tengo el honor de elevar a manos de V. E. un ejemplar del periódico El Progreso de Castilla, cuyo número ha sido denunciado. Se remite un ejemplar denunciado por el Ministerio Fiscal de la Audiencia de Burgos, pasando al juzgado de primera instancia de esta Capital para que se proceda criminalmente contra el autor de un artículo publicado en la primera plana de dicho periódico con el epígrafe Los reyes sueñan, por considerarlo injurioso a S. M. el Rey de España [...] El periódico republicano El Progreso de Castilla 
publica un artículo con el epígrafe "Los reyes sueñan" y concluye "se despidan para el extranjero" que considero denunciable y sobre el cual he llamado la atención del Sr. Fiscal de esta Audiencia a los fines que estime procedentes [12].

Según publicó La Correspondencia de España fueron detenidos Francisco Vega de la Iglesia, Antonio Luna y Nicolás Pasca [13]. Finalmente Pasca resultó el único condenado por la Audiencia provincial de Burgos a ocho años de prisión y a una multa de 500 pesetas "por desacato al rey" [14]. La condena fue ratificada por el Tribunal Supremo y en junio de 1884 ingresó en el presidio para cumplirla [15].

Poco después el periódico fue nuevamente denunciado y secuestrado por orden del gobernador por publicar la suscripción popular abierta a favor de las familias "del malogrado teniente Cebrián y de cuatro sargentos fusilados en Agosto (sic) último en Santo Domingo de la Calzada" [16]. El siguiente texto demuestra cómo la discrecionalidad de los gobernadores provocaba que un comentario o iniciativa periodística fuera perseguida en unos lugares y en otros no:

No nos explicamos el porqué de la denuncia del Progreso de Castilla (que como nuestros lectores sabrán ya se ha refundido en El Orden Público y si no lo sabían ya se lo decimos nosotros) si tal denuncia estriba en la suscripción abierta a favor de las familias de los sargentos fusilados en Santo Domingo. Además de que socorrer a los desgraciados es una obra meritoria a los ojos de Dios, hay periódicos en Madrid, Sevilla y Valencia, que siguen colocando en sus columnas las cantidades reunidas para aquel fin, sin que a gobernadores ni a fiscales se les ocurra poner obstáculo alguno. Por eso, repetimos, que no nos explicamos el porqué de tal denuncia [17].

El Orden, sucesor de El Orden Público y de El Progreso de Castilla, mantuvo también constantes roces con la censura. "Viene con más blancos que tiene un ejercicio de fuego", decía en sus páginas El Papa Moscas, para agregar que aparecía "blanqueado, y el hermano salía jalbegado y dado de lanilla" [18].

Tras la desaparición de El Orden se fundó La Voz del Orden Público, que tampoco se salvó de la persecución de la justicia y la censura. Nada más comenzar a publicarse se actuó contra él. De hecho, los problemas con la justicia no cesaron tras la desaparición de estos periódicos.

Otro periódico censurado y condenado fue El Correo de los Inocentes. De esta publicación sólo se editó un número en 1884, hecho por Francisco de Vega de la Iglesia, Antonio Luna y Lisardo Blanco, personajes vinculados a otros periódicos republicanos, entre ellos El Orden Público, El Progreso de Castilla, El Fomento... En este caso fue suficiente un solo número para condenar a prisión a su editor y para que el periódico no saliera más:

Se ha dictado auto de prisión contra el editor responsable de un periódico de inocentes, que apenas si vio la luz el día 28 de Diciembre. Probablemente y por fortuna el procesado no ingresará en la cárcel por haber puesto las 2.000 pesetas de fianza que le exigen. A este paso hasta el Boletín Oficial corre peligro. En todas partes cuecen habas, pero en esta tierra a calderadas ${ }^{[19]}$.

\subsubsection{Condenas por anticlericalismo}


La publicación del artículo "Los frailes" supuso que El Orden fuera denunciado de nuevo y sus ejemplares recogidos. En el artículo se criticaba a los religiosos. De ello se tiene conocimiento a través de este pasaje publicado en las páginas de El Heraldo de Castilla del 24 de julio de 1880:

¡Qué perspicacia tiene El Orden! Siempre toma el rábano por las hojas y luego dice en su denunciado y caritativo artículo (Los frailes) que los frailes tienen la cabeza triangular. Sepa El Orden que ni me acordaba que existía ni quería acordarme por lo poco acertado que se encuentra al tratar ciertos asuntos, pero ahora que me obliga a fijar en él, debo decirle que el lenguaje que emplea al hablar de los frailes es [...] poco fino, huele a hostería o menos, pretende hacer reír, inventando asuntos, y gracia que no tienen ninguna, y es injusto y es poco caritativo con las personas a las que alude, por eso le han recogido, mientras que con El Heraldo nadie se mete porque trata los asuntos con prudencia, y a los individuos con consideración que merece todo Español [...] El Orden dice que los frailes son gordos, sucios y crasos [...] Decididamente El Orden Público demuestra con estas tonterías que su cabeza no tiene el peso de la Ley.

Poco tiempo después se conoció la sentencia que condenó a este periódico a dos meses de suspensión:

Nuestro apreciable colega El Orden Público, ha sido condenado a dos meses de suspensión por el Tribunal de Imprenta. De modo que nos quedamos sin Orden Público hasta el mes de octubre. ¡Cómo ha de ser!, resignación hermano, y pasemos con orden el verano" [20].

A finales de septiembre el periódico pudo volver a su cita habitual con los lectores. Antonio Luna y Gómez, fue denunciado también por varios sueltos publicados en El Progreso de Castilla por "injuriar groseramente" a la comunidad de religiosos del Convento de La Vid. La denuncia fue interpuesta por Fray Tomás Fito y Zapatero en representación del Colegio de Agustinos Filipinos de la Vid. Se le embargó, como medida preventiva, por valor de 1.500 pesetas [21].

En 1884 la Audiencia de Burgos condenó a siete procesados de El Progreso de Castilla a la pena de cuatro años, once meses y once días de destierro a 25 kilómetros del pueblo de Cortes y una multa de 250 pesetas tras la denuncia interpuesta por el párroco de Cortes, Marcos Vugo, por injurias [22].

El Progreso de Castilla y La Voz del Orden Público fueron censurados por el Arzobispado de Burgos, de tal forma que se prohibió "gravísimamente a todos nuestros diocesanos la lectura de los mismos y mandamos a los que conserven algunos ejemplares que los entreguen a sus párrocos o confesores". Esta decisión se justificó en base a que una comisión de "sabios y prudentes teólogos" determinó que El Progreso de Castilla y tras su desaparición La Voz del Orden Público contenían "muchas proposiciones falsas, escandalosas, injuriosas al Clero secular y Regular, blasfemias impías, heréticas, perniciosas y obscenas" [23]. En esta resolución se advirtió además de que si La Voz del Orden Público proseguía con sus ataques a la Iglesia Católica "incurrirán por las penas 
fulminadas por la Iglesia" los directores y redactores del periódico, así como "los que cooperen en su publicación y los suscriptores". Fue una advertencia de excomunión, no solo para los periodistas, sino también para la imprenta, vendedores y lectores.

\subsubsection{El Ayuntamiento prohíbe el acceso a los periodistas}

La persecución a la prensa incómoda no solo se ejerció desde los tribunales de Justicia y la Administración central. Desde algunas instituciones, como el Ayuntamiento, se adoptaron resoluciones para impedir el acceso de los periodistas al Consistorio, con la finalidad de que no informaran de los asuntos municipales:

Por no sabemos qué discusión acerca de si La Voz de El Orden Público había de entrar o no en las oficinas municipales, la comisión que entendía del asunto ha propuesto -y por lo visto se ha acordado- que no penetre ninguno, absolutamente ninguno, de los periódicos que en Burgos se publican [24].

Era entonces alcalde de la ciudad Manuel de la Cuesta. Esta situación no supuso ni el cese de las críticas a los corporativos ni que se dejara de informar de los asuntos municipales:

Se habla con insistencia de la dimisión de nuestro alcalde. Aunque en su tiempo se ha verificado la expulsión de los periodistas de las casas consistoriales, lo sentiremos, porque no nos ha dado que hacer. $Y$ eso de arrojarnos del templo municipal como a los mercaderes de la Biblia, no nos afecta gran cosa. Ha tiempo que estamos acostumbrados a ciertas genialidades concejiles [25].

El Salón de Recreo, también propuso la expulsión de La Voz de El Orden Público. Finalmente, los socios votaron en contra de esta expulsión, y ello provocó la dimisión de algunos integrantes de esta sociedad, entre ellos la del presidente del Círculo.

\subsection{Los periódicos de Lisardo Blanco: El Fomento, El Criterio y El Popular}

Lisardo Blanco colaboró, fundó y dirigió un buen número de publicaciones de orientación republicana, socialista y anticlerical. Fundó El Fomento (1881-1882) y tras su desaparición El Criterio (1883-1884). Años más tarde, en 1887, volvió a refundarEl Fomento y en 1889 El Popular, que se fusionó con Burgos para dar paso a El Popular Burgalés.

Antes de El Fomento se publicó La Gaceta de la Administración, periódico que dirigió Francisco Vega de la Iglesia, tras abandonar por causas políticas la redacción del periódico republicano El Orden Público. Su primer ejemplar salió a la venta en noviembre de 1881. En el mismo también colaboró Pedro Hernando. No se sabe con exactitud cuánto tiempo duró, pero fue de vida efímera, ya que en 1882 dejó de publicarse y se integró en El Fomento, semanario político, dirigido y fundado por Lisardo Blanco, que se desapareció en junio de 1883. Tras la desaparición de este semanario, su director, Lisardo Blanco, fundó El Criterio (1883-1884). De periodicidad semanal, comenzó a publicarse el 6 de junio de 1883 y cesó en abril de 1884. En este nuevo proyecto participaron también Pedro Hernando y Lasso de la Vega. Duró menos de un año. 
El 11 de junio de 1887 El Fomento fue refundado de nuevo por Lisardo Blanco. No se sabe cuánto tiempo pudo estar editándose, aunque tras varios cambios de propietarios y fusiones, se conoce que alcanzó el siglo XX.

Su carácter de periódico polémico lo atestigua, no solo los regulares enfrentamientos con otras cabeceras conservadoras, católicas e incluso liberales, sino las habituales inserciones de "remitidos" (comunicados pagados) publicados en otros periódicos por particulares. En 1891, su director Fernando Lasso de la Vega, fue agredido en pleno centro de la ciudad por el Conde de Berberana:

un desagradable suceso que ha llamado la atención estos días. A las cuatro y media de la tarde del martes, y en los Portales de la Plaza, fue agredido vivamente el director de El Fomento por el Conde de Berberana. Parece que el periodista, en vindicación de su honor, ha llevado al aristócrata a los tribunales [26].

En 1893 Fernando Lasso de la Vega cedió la propiedad Pedro Hernando, Antonio Luna y Sixto Ruiz. Pedro Hernando, colaboró y formó parte anteriormente de La Gaceta de la Administración, reconvertida en El Fomento en 1882. Por su parte Antonio Luna estuvo vinculado al periódico La Unión Republicana y a las cabeceras de El Orden Público. Es decir, entre estas cabeceras y las diversas etapas de El Fomento hubo vinculaciones muy estrechas en línea editorial y entre los promotores e impulsores. No se sabe cuándo desapareció, pero se conoce que el 21 de enero de 1900 El Anunciador Burgalés (18991900) se fusionó con El Fomento, quedando esta última cabecera.

El Fomento, refundado por Lisardo Blanco, fue una cabecera de orientación ideológica inestable. Defensor del Partido Progresista Democrático, evolucionó hacia posiciones socialistas, de las que terminó renegando. Producto de su propia evolución ideológica, se alejó de las ideas programáticas del partido de Pablo Iglesias, a quién aconsejó que "si quieres hacer prosélitos de sus ideales vaya a buscarlos al presido". Incluso Lisardo Blanco llegó a retar a Pablo Iglesias a un debate, que no se llegó a celebrar:

El director de El Fomento, Lisardo Blanco, había retado públicamente al compañero Iglesias a una amplia discusión sobre el socialismo; aceptó el compañero, dejó su viaje para el jueves, pues el miércoles intentaba salir para Bilbao, se consiguió el permiso; se tiraron en la imprenta los carteles; invitó dicho señor Blanco a los abogados Fernández Izquierdo y Ruiz Llorente para que le hicieran coro en el debate. -Invitación que estos señores no aceptaron- y cuando todos esperábamos oír la lucha, que a la verdad hubiera sido entretenida, desiste del empeño el iniciador, marcha triunfante el compañero Iglesias y nos quedamos todos con treinta y una de mano. Estoy inconsolable desde que he perdido una función que tanto bueno prometía. ¡No puede menos que ande el mismo Salanova por medio! [27]

El 1889 Lisardo Blanco, desvinculado ya de El Fomento, se erigió como fundador de nuevos proyectos periodísticos con una orientación progresista, republicana y anticlerical, El Popular (1889) y Burgos (1889), que tras su fusión dieron paso a El Popular Burgalés (1889-1890) [28].

El Popular se publicó de 1889. Esta cabecera destacó por su vocación anticlerical y mantuvo regulares enfrentamientos con el periódico católico y carlista La Fidelidad 
Castellana. El Popular tuvo serias dificultades. Fue prohibido por el Arzobispado por sus críticas a los religiosos. Tuvo que buscar en Valladolid una imprenta, dado que en Burgos ninguna estaba dispuesta a seguir con su publicación:

Un periódico local recientemente apercibido y condenado por el señor Arzobispo, y que no encontraba imprenta en Burgos donde imprimirse, se trasladará a Valladolid, sin cambiar las tendencias ni el título. Esto al menos decían ayer los amigos del periódico en cuestión. Mal oficio este del periódico para hacerse en un lado y publicarse en otro. Pero sobre gustos no hay nada escrito [29].

Lisardo Blanco, fundador de El Fomento, El Criterio o El Popular, fue también uno de los precursores de la cabecera El Porvenir Social. Semanario imparcial y defensor de los intereses de los pueblos (1893-1893), transformado en El Porvenir Español (1893-1897) y en El Porvenir de Burgos (1897-?).

\subsection{De la Voz de la Industria a La Unión Republicana}

Entre 1891 y 1894 se sucedieron cinco cabeceras, que formaron parte de un proyecto periodístico común. Se trató de La Voz de la Industria y del Comercio. Semanario político independiente y mercantil, defensor de los intereses morales y materiales de la provincia (1891-1892), dirigido por Julián San Juan González. Tras su conversión en diario, fue absorbido el 1 de marzo 1892 por El Noticiero de Burgos (1891-1892), que dirigía Pedro Arraiz del Olmo, y que se postulaba como republicano:

el periódico El Noticiero aparece el domingo, declarándose republicano, y predicando paz y concordia [....] ¿Entre los príncipes cristianos? ¡No, hombre, no! Entre los afiliados al partido [30].

A pesar de ser diario, atravesó por diversas dificultades que hicieron que su periodicidad fuese irregular. Pasó a semanal para convertirse de nuevo en diario. El 30 de julio de 1892 El Noticiero de Burgos cambió su nombre por el de La Voz del Pueblo (1892-1894), periódico en el que también trabajó Nicolás Pasca. [31] Dos años más tarde, el 7 de abril de 1894, se fusionó con La Unión Republicana (1893-1894), conservando la denominación de La Voz del Pueblo, cuyo último número se publicó el 16 de noviembre de 1894.

La Unión republicana (1893-1894), fue un semanario fundado por Félix Cecilia Barbadillo y que desapareció el 7 de abril de 1894, cuando fue absorbido por La Voz del Pueblo. Se trató de un semanario político muy inestable, como lo demuestra el número de directores que tuvo en su corta vida. Dirigido primero por Francisco García, y posteriormente por Gumersindo Brioso, Aniceto Llorente, y Julio Díez Montero. Se publicaba los sábados en el establecimiento tipográfico de El Comercio a cargo de Antonio de Luna (quien estuvo en El Progreso de Castilla, El Orden Público, El Correo de los Inocentes, El Fomento...).

Pocos meses después de la desaparición de La Voz del Pueblo (cuyo último número fue del 16 de noviembre de 1894) se publicó La Revolución, periódico republicano de periodicidad bisemanal, que se editaba los miércoles y sábados y que estuvo dirigido por Gregorio Izquierdo Díez. Aunque se desconoce cuánto tiempo estuvo publicándose, se sabe que el primer número salió el 30 de marzo de 1895. 


\section{LOS PERIODISTAS}

Blanco y Álvarez, Lisardo. De ideología de izquierdas, republicano y anticlerical, tuvo problemas con la justicia y mantuvo intensos debates y enfrentamientos con otros compañeros periodistas, especialmente con Jacinto Ontañón, director y fundador de El Papa Moscas. Este le puso como apodo "tropezones".

Lisardo Blanco falleció el 12 de abril de 1906. Sus malas relaciones con otros periódicos quedan acreditadas en el escaso eco que tuvo su desaparición. El Papa Moscas insertó una breve referencia y lo mismo hizo Diario de Burgos, que se limitó a señalar que "el señor Blanco fue un periodista muy conocido que había pertenecido a las redacciones de muchas publicaciones burgalesas".

Fundador y director de El Fomento (1881-1883), El Criterio, El Correo de los Inocentes(del que sólo salió un número que tuvo problemas con la justicia), El Porvenir Español, El Regenerador, El Porvenir Social y El Popular. Publicó artículos en El Pueblo Español, El Porvenir de León... en los que expresó con vehemencia sus ideales sociales y políticos.

Compatibilizó la actividad periodística con su actividad profesional de funcionario público. En 1870 fue escribiente en la sección de cuentas municipales del Gobierno Civil de Burgos y tres años después fue ascendido a oficial. En 1902 alcanzó la plaza de jefe de la sección de Cuentas Municipales. Compatibilizó sus actividades periodísticas y profesionales con los negocios.

Díez Montero, Julio. Abogado que fue director de La Unión Republicana, Guasa Viva (que se refundió con El Papa Moscas), y de El Papa Moscas. De ideología liberal y republicano, fue un activo periodista político. En julio de 1918 cesó de forma voluntaria como director de El Papa Moscas, aunque siguió colaborando en sus páginas. Escribió también en El Pueblo, semanario democrático de Burgos del siglo XX, a cuya plantilla dejó de pertenecer en 1920 por problemas de salud.

Fue presidente del Partido Republicano de Burgos, por el que se presentó a las elecciones en 1920 [32]. Asimismo, fue elegido diputado provincial en 1894. Su compromiso con los obreros le llevó a pedir al Ayuntamiento que subvencionase a la Sociedad de Socorros Mutuos de obreros republicanos.

En 1916 se constituyó la Asociación de la Prensa de Burgos, de la que Mariano Rodríguez fue su primer presidente y Julio Díez Montero el tesorero. Fue asimismo presidente de la Junta directiva de la Sociedad Salón de Recreo.

Lasso de la Vega, Fernando. Natural de Lucena (Córdoba). Agente de comercio que fue concejal del Ayuntamiento de Burgos. Fue socio de Lisardo Blanco, con quién promovió y dirigió periódicos como El Criterio y El Fomento, que cedió en 1893 a Pedro Hernando y Telesforo Sixto Ruiz y Lázaro. Durante su estancia en Burgos colaboró en la práctica totalidad de cabeceras republicanas. Ingresó en prisión en varias ocasiones, consecuencia de sus artículos. 
Además de periodista y agente de negocios, fue un activo político. Corporativo en el Ayuntamiento de Burgos, se llegó a presentar para diputado provincial por el Partido Republicano Progresista.

Falleció en Lucena (Córdoba) en enero de 1900: "Repentinamente ha fallecido en Lucena D. Fernando Lasso de la Vega, que tras muchos años de ausencia de dicha ciudad, regresó a ella donde la ha sorprendido la muerte" [33].

Pasca, Nicolás. Destacó por su activismo político. Participó en proyectos periodísticos republicanos y de izquierdas, entre ellos El Progreso de Castilla y las cabeceras de El Orden Público. Fue condenado por la Audiencia provincial de Burgos a ocho años de prisión y a una multa de 500 pesetas "por desacato al rey" por el artículo "Los reyes se van”, que publicó en El Progreso de Castilla. La condena fue ratificada por el Tribunal Supremo y en junio de 1884 ingresó en el presidio de Burgos [34]. Un año antes, en 1883 Nicolás Pasca fue también detenido e ingresó en el presidio, junto a Francisco Vega de la Iglesia y el repartidor de El Orden Público, acusados de "publicación clandestina" [35].

Pasca compatibilizó su actividad como periodista con la de trabajador no cualificado, aunque instruido. Se conoce que representó en Burgos los productos de ultramarinos de C. Castilla y Compañía, así como que optó a una plaza de conserje en el Teatro Principal, aunque no le fue concedida.

Vega de la Iglesia, Francisco. Nacido en Burgos y fallecido en Sevilla, fue abogado y periodista. Director de D. Javier, Ecos de Burgos, Martinillo, La Gaceta de la Administración, El Fomento y El Progreso de Castilla, todas publicaciones de corta vida. Colaboró también en El Orden Público, periódico del que se marchó por diferencias políticas y en el que ejerció como director interino. Participó también en el único número que se publicó de El Correo de los Inocentes. Sus ideas revolucionarias le llevaron a tener que hacer frente a numerosos procesos judiciales y sufrir penas de cárcel.

Perteneciente a una familia de ideas progresistas y republicanas, muy vinculada a la actividad política. Hijo de Nicolás de Vega, también abogado y natural de Castrojeriz (Burgos), y Telesfora de la Iglesia, contrajo matrimonio en Bilbao en 1887 con Segunda Manteca.

Perteneciente al Partido Republicano Progresista y al Partido Liberal Progresista, fue candidato a diputado a las Cortes y abandonó Burgos en 1885, tras obtener la licenciatura en Derecho por la Universidad de Valladolid, para residir en Bilbao, donde continuó con su actividad política. Su hijo Ernesto llegó a ser entre 1931 y 1939 gobernador de Cádiz, Granada, Gran Canarias, Guadalajara, Burgos y Albacete, siendo fusilado en esta última ciudad el 16 de noviembre de 1939.

\section{CONCLUSIONES}

En el siglo XIX, Burgos fue una ciudad conservadora, en la que las élites políticas y económicas tenían un especial protagonismo. Gran importancia e influencia tuvieron el Ejército que, con su importante presencia, se convirtió en uno de los bastiones económicos de la ciudad; y la Iglesia, que controlaba la educación y que dispuso de una red de periódicos para potenciar su poder e influencia. 
En este contexto de ciudad tradicional y religiosa, surgió una prensa republicana y anticlerical, que se inició en el último cuarto de siglo, coincidiendo con una legislación más favorecedora de la libertad de prensa y con la aparición de movimientos sociales y políticos republicanos y obreros que se extendieron por todo el territorio nacional.

Fueron una veintena de cabeceras de vida muy efímera, auspiciadas por un grupo de intelectuales, que estuvieron presentes de formar repetida en los diferentes proyectos. El cierre de una cabecera suponía que se fundara otra con nombre similar o diferente, pero con orientaciones idénticas.

Estos periódicos, de los que ninguno de sus ejemplares se ha conservado, tuvieron grandes dificultades y desaparecían al poco de su nacimiento. Los editores, directores y periodistas se enfrentaron a la censura y a sanciones económicas, y, en algunos casos, fueron condenados a penas de prisión, constituyendo el caso más grave el de Nicolás Pasca, que fue condenado a ocho años de cárcel. Se trató, en algunos casos, de políticos que participaron en la actividad electoral y que defendieron sus ideas a través de las cabeceras que fundaron, y en otros, de periodistas de segunda ocupación que tenían una actividad económica principal, abogados, agentes de negocios...

Los gobernadores ejercieron una fuerte presión política de control y censura. Pero además las instituciones burgalesas, como el Ayuntamiento o la Iglesia, actuaron igualmente contra estas cabeceras. El Arzobispado y buen número de religiosos llevaron a cabo actuaciones judiciales, que supusieron condenas, y de presión religiosa, mediante resoluciones de excomunión y prohibición de su lectura.

Los periódicos republicanos, socialistas y anticlericales tuvieron que hacer frente a una estructura institucional que presionó y provocó su desaparición. Esta estructura estuvo conformada por los poderes políticos y eclesiásticos.

\section{REFERENCIAS BIBLIOGRÁFICAS}

\section{Libros}

ALMUIÑA FERNÁNDEZ, C. (1996). La prensa vallisoletana durante el siglo XIX. Valladolid, Servicios de publicaciones de la Diputación provincial.

ÁLVAREZ LÁZARO, P. F. (2002) Cien años de educación en España. Madrid. Ministerio de Educación.

AUBERT, P. (1996). Religión y Sociedad en España (siglos XIX y XX). Madrid. Casa de Velázquez.

CÁRCEL ORTÍ, V. (1988). León XIII y los católicos españoles. Informes vaticanos sobre la Iglesia en España. Pamplona. Eunsa Ediciones.

CARR, R. (2008). España 1808-1975. Barcelona. Ariel Historia.

CASTRILLEJO IBÁÑEZ, F. “2007). Burgos y los burgaleses en el siglo XIX. Burgos. Institución Fernán González. 
CHOMÓN SERNA, J.M. (2017). Burgos: Prensa y periodistas burgaleses del S XIX. Madrid. Editorial Fragua.

HERGUETA DOMINGO (1929). La imprenta en Burgos y su provincia 1475-1920. Tomo IV. Burgos. Obra inédita.

MOLINA MARTÍNEZ, J.L. (1988). Anticlericalismo y literatura en el siglo XIX. Murcia. Servicio de Publicaciones de la Universidad de Murcia.

SÁNCHEZ ILLÁN, J.C. (1999). Prensa y política en la España de la Restauración. Rafael Gasset y El Imparcial. Madrid. Biblioteca nueva.

SEOANE, M.C. y Dolores SAIZ, M. (2007). Cuatro siglos de periodismo en España. Madrid. Alianza Editorial.

TIMOTEO ÁLVAREZ, J. (1981). Restauración y prensa de masas. Los engranajes de un sistema (1875-1883). Pamplona. Universidad de Navarra.

\section{Capítulos de libros}

GUEREÑA, J.L.: Las estadísticas oficiales de la prensa. En BARRERÉ et al (1987): Metodología de la prensa española. Madrid. Siglo XXI de España Editores.1982, pp. 81118.

REVUELTA GONZÁLEZ, M.: El anticlericalismo español en el siglo XIX. En AUBERT DESVOIS (2002). Religión y Sociedad en España. Siglos XIX y XX. Madrid. Casa Velázquez, pp. 155-178.

\section{Artículos en revistas}

CASTRILLERO, F. y FERNÁNDEZ, A.: "Aproximación a un estudio de las élites castellanas durante la Restauración”. Burgos. Boletín de la Institución Fernán González (BIFG). Año LXXIII, nº 9, 208, (1994), pp. 141-161.

CAZOTTES, G. y RUBIO, R.: "El auge de la prensa periódica”. Biblioteca Virtual Miguel de Cervantes, (2012), http://www.cervantesvirtual.com/nd/ark:/59851/bmckw625

GABRIEL de, N.: "Alfabetismo, semialfabetismo, y analfabetismo en España (1860-1991)". Revista Complutense de Educación. Vol. 8, n¹, (1997), pp. 199-231.

HERNÁNDEZ FUENTES, M.A.: "Velar por la fe y las costumbres. Censura eclesiástica sobre la prensa zamorana durante la Restauración". Revista Internacional de Historia de la Comunicación, nº 6, (2016), pp. 61-81.

HIGUERAS CASTAÑEDA, E.: "Prensa y partido en el republicanismo progresista: El Porvenir (1882-1885). Historia Contemporánea, 50 (2014), pp. 41-73.

LOUZAO VILLAR, J.: "La creación de un marco de sociabilidad anticlerical. El caso vizcaíno durante la Restauración”. Historia Social, n²73, (2012), pp. 59-79. 
MARIMON RIUTORT, A.: "En tierra hostil. La prensa diaria republicana en las Islas Baleares durante la Restauración Canovista (1879-1894)". Historia Contemporánea 48, (2013), pp. 245-281.

MARTÍN, L.P.: “Las logias masónicas: una sociabilidad pluriformal”. Hispania LXIII/2, nº 214, (2003), pp. 523-549

[1] Ministerio de Gobernación. 18 de mayo de 1880. Legajo $n^{\circ} 50$. Signatura y Topográfico (08)2544/00189. Archivo General de la Administración

[2] Ministerio de Gobernación. 21 de agosto de 1880. Legajo $n^{\circ} 101$. Signatura y Topográfico (08)2544/00189. Archivo General de la Administración

[3] Gobierno Civil de Burgos. Legajo no 125. Signatura y Topográfico (08)2544/00189. Archivo General de la Administración

[4] El Papa Moscas (1883). № 279, del 17 de junio, p. 2

[5] Ministerio de la Gobernación. 1880. Legajo n 1894: 34. Archivo Histórico Nacional

[6] El Papa Moscas (1883). № 295, del 7 de octubre, p. 2-3

[7] El Papa Moscas (1883). N²93, del 23 de septiembre, p. 2

[8] El Eco de la Provincia (1883). № 1.247, del 11 de octubre, p. 3

[9] El Buque de San Águeda era la referencia que los periodistas y periódicos de Burgos hacían cuando hablaban del Centro Penitenciario

[10] Gobierno Civil de Burgos. 16 de enero de 1880. Legajo $n^{\circ} 12$. Signatura y Topográfico (08)2544/00189. Archivo General de la Administración

[11] El Papa Moscas (1880). No 101 del 1 de febrero, p. 3

[12] Gobierno Civil de Burgos. Denuncia del periódico El Progreso de Castilla. 10 de junio de 1883. Leg. 12. Signatura y Topográfico (08)2544/00189. Archivo General de la Administración.

[13] La Correspondencia de España (1883). № 9.218, del 18 de junio, p. 1

[14] El Eco de la Provincia (1884). No 1.327, del 30 de enero, p. 2

[15] Crónica Meridional (1884). № 7.287, del 1 de julio, p. 2

[16] La Unión Democrática (1883). № 1.540, del 11 de noviembre, p. 3

[17] El Papa Moscas (1883). № 294, del 30 de septiembre, p. 2

[18] El Papa Moscas (1883). № 288 del 19 de agosto, p. 3

[19] El Papa Moscas (1885). № 364, del 1 de febrero, p. 3 
[20] El Papa Moscas (1880). № 128, del 1 de agosto, p. 3

[21] Semanario Católico (1883). № 678, Tomo $3^{\circ}$ Año III, del 1 de diciembre, p. 10

[22] Semanario Católico (1884). № 127, Tomo $3^{\circ}$ Año IV, del 1 de febrero, p. 8

[23] Boletín del Clero Obispado de León (1884). № 1, Tomo XXXII, del 3 de enero, p. 15

[24] El Papa Moscas (1883). № 307, del 30 de diciembre, p. 3

[25] El Papa Moscas (1884). N o 309, del 13 de enero, p. 3

[26] El Papa Moscas (1891). № 694 del 12 de abril, p. 3

[27] El Papa Moscas (1888). N 529 del 1 de abril, p. 3

[28] La Fidelidad Castellana (1889). № 1841, del 22 de junio, p.1

[29] El Papa Moscas (1890). № 636 del 2 de marzo, p. 3

[30] El Papa Moscas (1892). № 741 del 6 de marzo, p. 3

[31] La Voz del Pueblo. En El Papa Moscas (1892). № 767 del 4 de septiembre, p. 2

[32] El Pueblo (1920). Nº 61, del 17 de enero, p. 1

[33] Diario de Córdoba (1900). № 14.681, enero, p. 3

[34] Crónica Meridional (1884). № 7.287, del 1 de julio, p. 2

[35] El Eco de la Provincia (1883). № 1.247, del 11 de octubre, p. 3

\section{BREVE SEMBLANZA DEL AUTOR:}

José María Chomón Serna: Licenciado en Periodismo y Derecho y Doctor en Comunicación Audiovisual. Ha sido redactor de Radio Nacional de España (RNE) en Burgos durante 30 años y en la actualidad es profesor de la Universidad de Burgos. Autor de libros y artículos científicos sobre el periodismo de proximidad y la historia del periodismo.

- Recibido: 13/11/2017

- Aceptado: 19/03/2018

Ámbitos. Revista Internacional de Comunicación, n.40, edición de primavera, 2018. 